\title{
Performance Tests - Update on USP Activities
}

Margareth R. C. Marques

United States Pharmacopeial Convention, Inc., Rockville, MD, USA

e-mail:mrm@usp.org

\section{PHARMACOPEIAL FORUMS}

The European Pharmacopoeia (EP), Japanese Pharmacopoeia (JP), and United States Pharmacopeia (USP) participate in the process of harmonization of general chapters and excipients monographs (1). Each of these pharmacopeias publishes proposals for revisions in their respective pharmacopeial forums for public comments as follows:

- EP: pharmeuropa.edqm.eu/home

- JP: www.pmrj.jp/eng/02/jpf_contents.html

- USP: www.usppf.com (published every 2 months, 90-day period for comments).

\section{DISINTEGRATION}

The USP general chapter $<701>$ Disintegration is partially harmonized with the EP and JP (2). The EP is coordinating a revision to the Disintegration chapter to include the apparatus for large dosage forms described in the USP general chapter <2040> Disintegration and Dissolution of Dietary Supplements, under Apparatus B (3). This equipment is used for dosage forms that are longer than $18 \mathrm{~mm}$. The proposal for this revision will be published soon in the respective pharmacopeial forums for public comments.

\section{PERFORMANCE TESTS FOR SEMISOLID DOSAGE FORMS}

In May 2019, the U.S. FDA issued the guidance, "Maximal Usage Trials (MUsT) forTopically Applied Active Ingredients Being Considered for Inclusion in an Over-The-Counter Monograph-Study Elements and Consideration" (4). This guidance identifies the need for additional safety data for ultraviolet (UV) filters, including dermal absorption data that can be obtained from MUsT studies. FDA guidance recommends conducting an in vitro skin permeation test (IVPT) to select products for MUsT studies and for use as an alternative to test the final product formulation composed of GRASE (generally recognized as safe and effective) ingredients only.
In July 2019, the workshop "Topical Drug Development - Evolution of Science and Regulatory Policy" took place at the University of Maryland, School of Pharmacy. This meeting brought together stakeholders from the FDA, academia, and industry to discuss the MUsT program, including the successful incorporation of MUsT in drug development and utilization of in vitro methods in product development. In a recent publication, Matta et al. demonstrated the systemic absorption of sunscreens applied topically, which supports the need for additional studies to determine the clinical significance of these results (5).

As a consequence of these discussions and findings, a revision to the USP general chapter <1724> Semisolid Drug Products - Performance Tests was initiated (6). The current version of this chapter discusses the equipment and parameters used to evaluate in-vitro release tests (IVRT) of semisolid dosage forms such as ointments, creams, gels, etc. Typically, IVRT are used during product development and for post-approval changes, and a synthetic membrane is used to hold the sample in the equipment. This membrane cannot interfere with the release characteristics of the product being evaluated. The revision to $<1724>$ will include an update on the equipment that can be used for IVRT and IVPT including their qualification, method development and validation, skin requirements, etc. The proposed update to $<1724>$ is tentatively scheduled for publication in Pharmacopeial Forum by the end of 2021.

\section{NEW ADVANCEMENTS IN PRODUCT PERFORMANCE TESTING}

In mid-2019, an expert panel was created to provide recommendations for the adoption of product performancetests, development of innovativeapproaches for novel dosage forms in USP monographs and general chapters, and to evaluate the current compendial product performance tests (dissolution, disintegration, and drug release), considering the latest developments in the field. In addition, the panel will explore possibilities 
for performance testing of drug products containing nanomaterials and those in continuous manufacturing. The panel is composed of experts from the FDA and international representatives from academia and industry. This panel coordinated the USP workshop on "Advancements on In Vitro Performance Testing of Drug Products," held at the USP headquarters in December 2019 (7). The recommendations of this expert panel will be published in future issues of Pharmacopeial Forum.

\section{REFERENCES}

1. Pharmacopeial Discussion Group (PDG). United States Pharmacopeial Convention, Inc. website. https://www.usp.org/ harmonized-standards/pdg. Accessed January 18, 2021.

2. <701> Disintegration. In The United States Pharmacopeia and National Formulary USP 41-NF 36; The United States Pharmacopeial Convention, Inc.: Rockville, MD, 2018.

3. <2040> Disintegration and Dissolution of Dietary Supplements, under Apparatus B. In The United States Pharmacopeia and National Formulary USP 41-NF 36; The United States Pharmacopeial Convention, Inc.: Rockville, MD, 2018.

4. Maximal Usage Trials for Topically Applied Active Ingredients Being Considered for Inclusion in an Over-The -Counter
Monograph: Study Elements and Considerations; Guidance for Industry; U.S. Department of Health and Human Services, Food and Drug Administration, Center for Drug Evaluation and Research (CDER): Silver Spring, 2019.

5. Matta, M. K.; Florian, J.; Zusterzeel, R.; Pilli, N. R.; Patel, V.; Volpe, D. A.; Yang, Y.; Oh, L.; Bashaw, E.; Zineh, I.; Sanabria, C.; Kemp, S.; Godfrey, A.; Adah, S.; Coelho, S.; Wang, J.; Furlong, L-A.; Ganley, C.; Michele, T.; Strauss, D. G. Effect of Sunscreen Application on Plasma Concentration of Sunscreen Active Ingredients: A Randomized Clinical Trial. JAMA 2020, 323, 256-267. DOI: 10.1001/jama.2019.20747.

6. <1724> Semisolid Drug Products - Performance Tests. In The United States Pharmacopeia and National Formulary USP 41-NF 36; The United States Pharmacopeial Convention, Inc.: Rockville, MD, 2018.

7. Hermans, A.; Dorozynski, P.; Muzzio, F. J.; Li, H.; Nielsen, S.; Chen, S.; Reppas, C.; Klein, S.; Patel, S.; Wacker, M.; Thakker, K.; Pruessmann, K.; Seidlitz, A.; Ghosh, T. K.; Yang, Y.; Willett, D.; Hochhaus, G.; Tay, J.; Liew, C. V.; Heng, P. W. S.; Sun, C. C.; Kraemer, J.; Marques, M. R. C. Workshop Report: USP Workshop on Advancements in In Vitro Performance Testing of Drug Products. Dissolut. Technol. 2020, 27, 52-70. DOI: 10.14227/DT270220P52. 